\title{
Open spaces and environmental design
}

\author{
PhD. Eng. M. Rotilio and Prof. Eng. P. De Berardinis, Department of Civil Architecture, Environmental \\ Engineering, University of L'Aquila, Italy
}

\begin{abstract}
The urban fabric of any human settlement can be analyzed at two levels: the built fabric and the system of empty spaces. Graphically, the two levels are contrary to each other. The first is the structure generated by the aggregation of the elementary unit that represents its governing and invariable element. It is a component that can be managed and its spatial, functional and structural entity can be controlled due to its "box like" structure. The empty system consists of public and private open spaces that form a network of relational, representative and social spaces but also an interconnecting system. So, the identification of the methods to analyze the environmental characteristics of these empty spaces and, therefore, the criteria to improve the comfort conditions of the users, is the aim of this research. The survey follows the branch of research that studies the methods of intervention in historical centers. The need to carry out project interventions in historic urban fabrics pushes the researchers to find the methods to introduce the comfort levels required by contemporary users and, at the same time, to respect the values to pass down to posterity The choice of a strategy involving a certain degree of invasiveness and reversibility depends on the designer's knowledge of the particular context of intervention For this reason, the project carried out in a context having important values, as it is a minor center, requires a detailed cognitive analysis of the site under study that, inevitably, will limit the designer's freedom. The study area is located in the Abruzzi Region, full of minor historical centers rich in deep cultural values..
\end{abstract}

Keywords-Open Spaces, Rehabilitation, Environmental design

\section{INTRODUCTION}

Open spaces are the social and connective areas of the urban core: whether public or private, identifiable as social areas or spaces of connection, arisen from human needs for social relationship, from human inborn need for contact and confrontation with his peers, or from the functional needs of movement and connection, they perform a role of cohesion of the urban built fabric [1]."

Over the centuries open spaces have assumed key roles, becoming often symbols and elements of recognition of different peoples and cultures. For years, contemporary architecture has been considering the design of a square as a meeting place, an area for social exchange, or location for important historical events. Today, the design of open spaces incorporates new issues, related to the control of urban microclimate, the search for comfort conditions and human well-being, and also for energy savings and natural ecosystem preservation.

Any open space project involves several difficulties in the design of the environmental parameters that determine comfort conditions. This is because the open space system is not a confined space and it is vulnerable to macro-climate variability For this reason these spaces are very often

deserted, unable to fulfill the original function assigned to them by the designer, because actually they are not uncomfortable. Considering the above mentioned issues, the identification of an action method is necessary to find design strategies that enhance comfort in open spaces. This methodology should be seen as a tool for an "open-space-aware" design.

\section{THE METHODOLOGY}

The urban microclimate is determined by two types of different factors: morphological parameters , related to urban form, degree of slope, height, and distribution of buildings, and environmental parameters, determined by the conditions of sun exposure, soil moisture, ventilation conditions. Therefore, the objective is to perform some analyses to deepen the relationship between the urban fabric and the climate can be carried out, with reference to the global and local climate data, taking into account also the morphological and topographical conditions of the site. These analyses will help to identify the areas of critical environmental concern in relation specific parameters, such as sun exposure, humidity and ventilation. The methodology to identify the above mentioned areas has been developed and validated through a detailed study of some case-studies [2 ]. Such study focuses on comfort conditions in open spaces in relation to the methods to control the effects of wind ventilation in summer and winter.

\section{WIND VENTILATION}

The wind is one of the most important factors affecting comfort conditions in open spaces [3].

The management of an environment exposed to the wind is difficult because it is influenced by several factors at global, regional and local levels. The wind comes from the motion of air from high- pressure areas towards low pressure areas. Its speed and direction depend on global factors but are subsequently influenced by the territorial morphology, or by the presence of natural elements such as mountains, hills, trees, or artificial elements such as built fabrics, squares, open spaces.

Therefore it is important to understand that the conditions of wind exposure may significantly vary from one side of the town to another or even from one side of a square to another. Furthermore, the wind is not a constant phenomenon in an area, either in terms of presence or direction and intensity. From an engineering point of view, the effects deriving from the presence of the wind in a territory are important from a double perspective, mechanical and thermal [4]. In fact, if the check of the stability of a structure to the horizontal action of 
the wind is necessary, the identification of the direct effects of the wind in terms of user comfort is likewise needed. These conditions depend from different variables including the activities that people are doing, the clothes they are wearing, the conditions of sun exposure [5], [6], [7].

Needless to say, the presence of wind ventilation may be a pleasant condition, for example in summer, or unpleasant in winter.

The variables that define wind characteristics are essentially two, namely the average speed and the wind direction. The study of the above mentioned characteristics is not simple, because they are normally measured by meteorological stations located in the countryside, which record data in relation to streams that are about ten meters from the ground level. Information about the winds can be found also in the atlas which collect data with the wind roses of different parts of the country. The wind rose is a graphical summary of local wind speeds and directions relating to a specific site, based on measurements over a long period of time

However, if the analysis of the data about the wind flow in open spaces is not particularly difficult and can be applied to heights greater than those of the urban area, on the contrary it becomes more complex when these open spaces are located in areas where there are local obstructions, such as buildings that dominate the windy area. This is because the introduction of artificial obstacles strongly increases the number of variables to take into account and as a consequence, accurate calculations and simulations are required to obtain a scientifically valid forecast. For this reason, the management and control of the wind flow in urban pedestrian areas is difficult because even slight changes in the configuration of the space or of the surrounding area can strongly influence and change the "shape" of the wind in space.

To date, in addition to real measurements performed on-site or in the wind tunnel, a computer model can be used to simulate the flow of air.

The implementation of real measurements offers the advantage of delivering results coming from the real situation. However, this method is particularly expensive because measurements need to be performed for relatively long periods in order to get reliable results. Of course, if the site under study is the result of a design work it is not possible to take measurements.

The wind tunnel tests have the advantage of giving reliable results rather quickly, they also allow to test the wind environment in areas of new design helping the designer to choose the best configuration. However, an experienced wind laboratory and an accurate model of the involved areas are required for this type of testing, which is the reason why the wind tunnel tests can be quite expensive.

A possible alternative to the two above mentioned systems is to develop a computerized model of the space and the surrounding area to simulate the air flow through CFD simulations or "Computational Fluid Dynamics".

These last two instruments, namely the wind tunnel and the construction through a computerized model, can be particularly useful in the design of a new open space.

For example, the simulations help the designer to understand what should be the orientation of the open space with respect to the wind flow to get the best conditions of comfort, its height in relation to the surrounding buildings, its size in the plant. Moreover, these simulations can be used even when the intervention has to be carried out in an already existing context. They are particularly efficient when the intervention is carried out in a complex urban fabric of a minor historic center, where there is a significant interpenetration between public and private space, between built fabric and open spaces. In fact, the urban fabric of a minor historic center is composed of the built fabric and the open spaces, two systems that appear to be the negative of one another, or the complement of one another. The minor centre object of the study is the village of Colonnella, located in the Province of Teramo, which belongs to a wide system of minor historic centers scattered in the inland areas of the Abruzzi region (see Fig. 1).

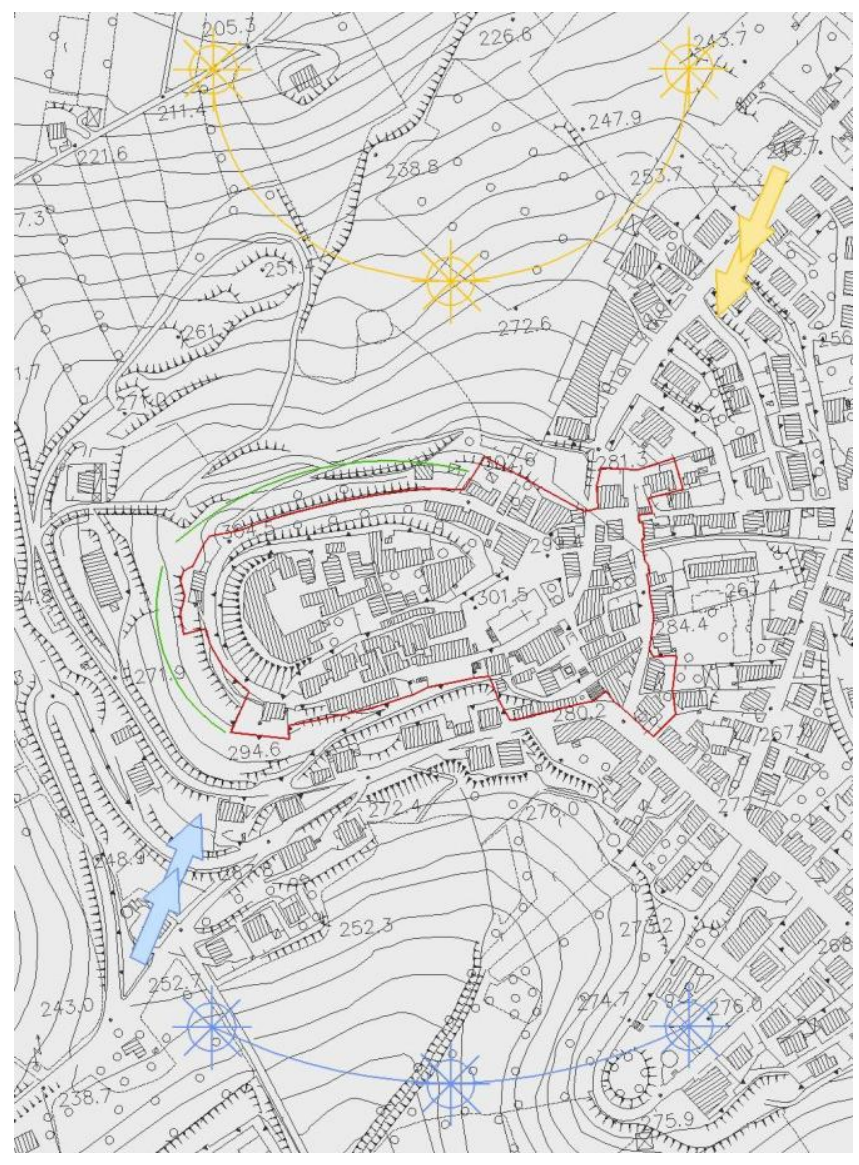

Fig. 1 The environmental features of Colonnella (Te).

The red line identifies the historical center. The yellow arrow indicates the direction of prevailing summer wind arising from the northeast; the blue arrow the prevailing wind in winter from the south-west.

\section{THE CASE STUDY}

The minor center of Colonnella is located on top of a hill, about $330 \mathrm{~m}$ above sea level, reachable by a spiral-shaped route that goes up to the highest town squares. The village consists of an historic nucleus of the late Middle Ages and a more recent district located in the eastern area. The historic centre has a compact shape, organically linked to other portions of the village but distinct from them due to its marked orographic conformation.

There are few architectural masterworks, symbol of a 
minor architecture.

The conformation of the urban fabric of Colonnella has not undergone many changes in the last few centuries. Most of the construction works that can be noticed concern single buildings rather than sizeable portions of the urban fabric, like for example volumetric additions or introduction of new building envelopes. In rare cases, demolitions have been carried out, aiming at the creation of empty spaces in the urban fabric rather than at the construction of new units or the restoration of formal features. The urban design has been strongly influenced by the morphology of the territory, the road network and a dense network of narrow streets and stairways that densely fractionate the oldest nucleus of the village located in the southern side.

The predominant building type is the terraced house, probably deriving from the medieval detached house on several levels, whose origin cannot be easily determined because of the many changes it has undergone over the years, like for example changes of use, or volumetric and superficial additions.

As mentioned before, the village of Colonnella is located on a hill that is less than $5 \mathrm{~km}$ from the Adriatic coast (as the crow flies) that influences it. Therefore, precisely because of its conformation, ventilation strongly influences the urban microclimate and, more specifically the comfort conditions of the open spaces that are the object of this study.

For this reason, a fluid-dynamic analysis of the site has been performed through an add-on of the Ecotect software called Winair. This analysis has been preceded by the construction of a three-dimensional model of the village which, later, has been imported into the software (see Fig. 2)

Through the above-mentioned tool some plans that intersect the three-dimensional model of the village (see Fig. 3) have been identified, near which the main characteristics of the wind namely direction, intensity and temperature are shown and marked by means of arrows and small colored squares. One of the most interesting aspects of the study is that the performance of these arrows is able to highlight the variation that the wind flows undergo in the moment when they interact with the urbanized context.

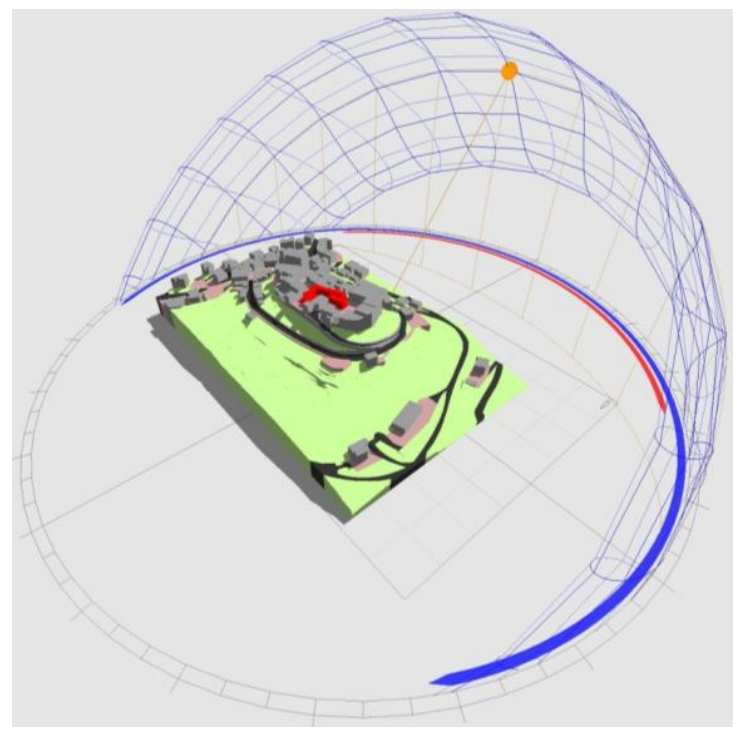

Fig. 2 The solar diagram of Colonnella, realized by Ecotect.

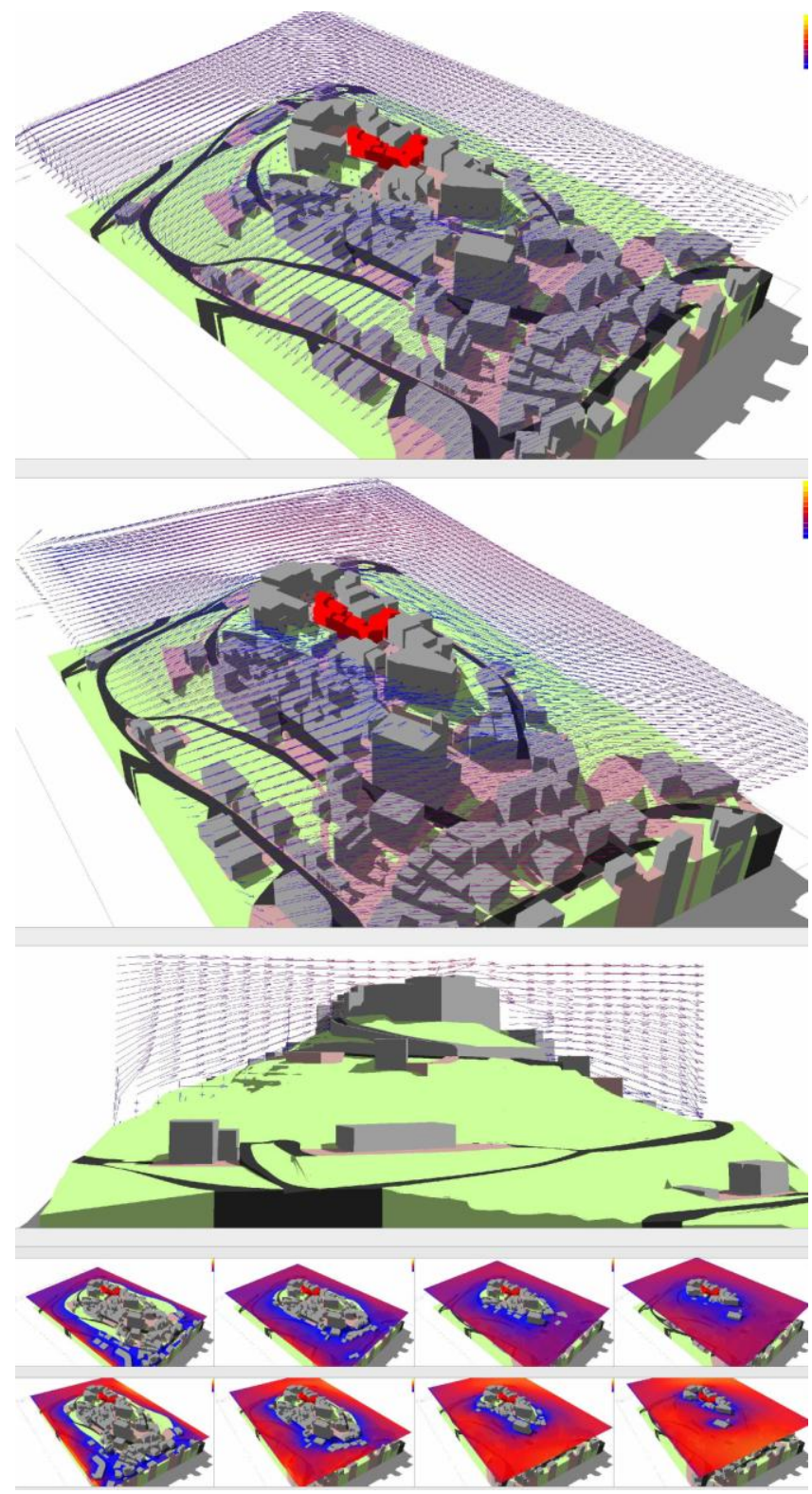

Fig. 3 The three-dimensional analysis of the wind in Colonnella. To understand the interaction between the winds and the buildings, we assimilate the first to plans at different altitudes that intersect the urban fabric.

The above described interactions generate the main phenomena that modify and perturb the wind flows and that mainly influence the conditions of the local micro-climate. They are known as the wind-blocking effect, the channel effect, the Venturi effect and the wind shadow effect, together with many others that are not mentioned here. The wind blocking effect is a phenomenon of reduction of the wind speed occurring when an obstruction is placed perpendicular to the wind flow. The channel effect is when the wind flows, encountering urban canyons (large urban streets), in parallel to their direction, funnel into them and produce high ventilation in these spaces. The Venturi effect is when there is a narrowing of the road section leading to an increase of the wind speed. Finally the so-called "wind-shadow effect" occurs in those areas that are sheltered from the wind, generally located in the rear side of the buildings with respect to the side exposed to the wind impact [8]. 

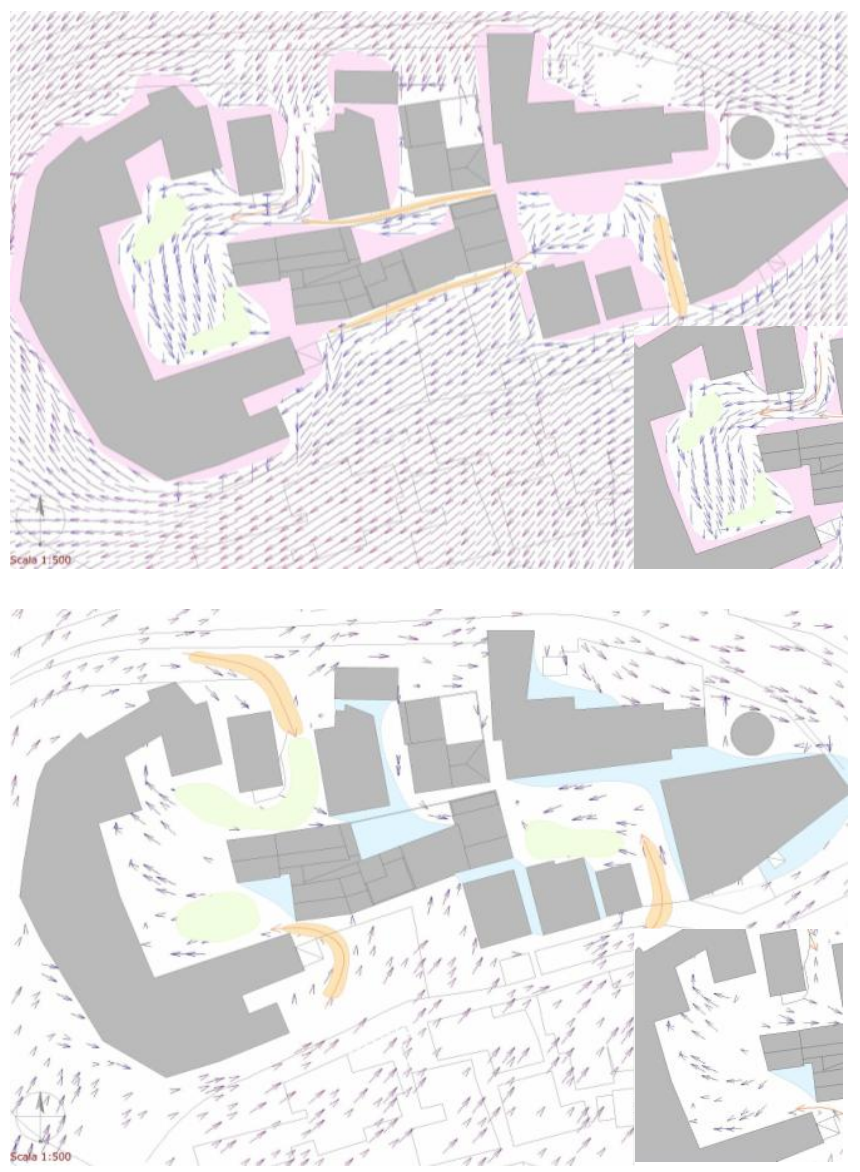

Fig. 4 The summer ventilation (above); the winter ventilation (below). In evidence, one of the part of interest for the project.

In the analysis carried out in the village under study, wind-shadow areas, wind channeling areas and areas of turbulence have been identified (see Fig. 4). Regarding the seasons, during summer the above-cited phenomena occur with greater intensity.

If in summer these phenomena do not cause significant problems to the conditions of comfort for users under certain conditions of sunshine and moisture, obviously it is not the same in winter.

In fact, turbulence and wind-channel effect cause discomfort conditions to users in the two major open spaces of the village, namely the squares located at the eastern and western ends of it (respectively Piazza Trento e Trieste and Largo Palazzo). Similar conditions of discomfort also occur in some narrow streets and little squares of the urban center.

The presence of numerous wind-shadow areas, like for example in Via Plebiscito must not be underestimated because the wind-shadow effects, in the absence of sunshine and high humidity on the ground, could cause water stagnation and molds. These events occur in their turn in the presence of impermeable soils (see Fig. 5) with low slope, associated with poor ventilation and solar penetration to the ground.

The briefly described methodology was applied to the above-mentioned open spaces like Piazza Trento e Trieste, Via Largo Palazzo and Via del Plebiscito as they are the most important social spaces of the village, often used to host temporary exhibitions and small concerts. The biophysical and bioclimatic analysis, that is the essence of our proposed methodology, showed that there are some critical areas in the above mentioned open spaces. In winter, the criticality is determined by the persistent shady conditions, the high impermeability of the soil and obvious stagnation (see Fig. 6 ), besides the above described effects of wind ventilation. In summer, the discomfort conditions, though less marked, are caused primarily by the high level of ventilation present in the minor center that determines localized points of turbulence. Still referring to the summer season, there are no other environmental problems since the three sites under study are quite protected against solar radiation and, considering the low level of seasonal rainfall, there are no phenomena of stagnation and humidity.

Once identified the critical environmental issues through the bio-climatic and biophysical analysis, the research has developed the intervention strategies aimed at mitigating the discomfort conditions in the open spaces of the village. Among them there is the introduction of vegetation serving as windbreaks, the arrangement of the pavement of the square to collect rainwater and the introduction of cooling systems.

All the design solutions have been developed in the light of the historic values of the village that must be preserved so to be handed down to posterity, identifying the most compatible and sustainable solutions. Vegetation has been introduced in the open spaces to improve the conditions of comfort together with wooden pavements that facilitate water drainage to eliminate the problem of moisture created by the stagnation of rainwater. Furthermore, systems to harvest and reuse water for irrigation and spraying mist water have been also used. The cooling mist systems operate through nozzles integrated into the PV systems. The atomization of water is achieved by forcing water by means of a high pressure pump that produces an ultra fine fog of millions of water droplets.

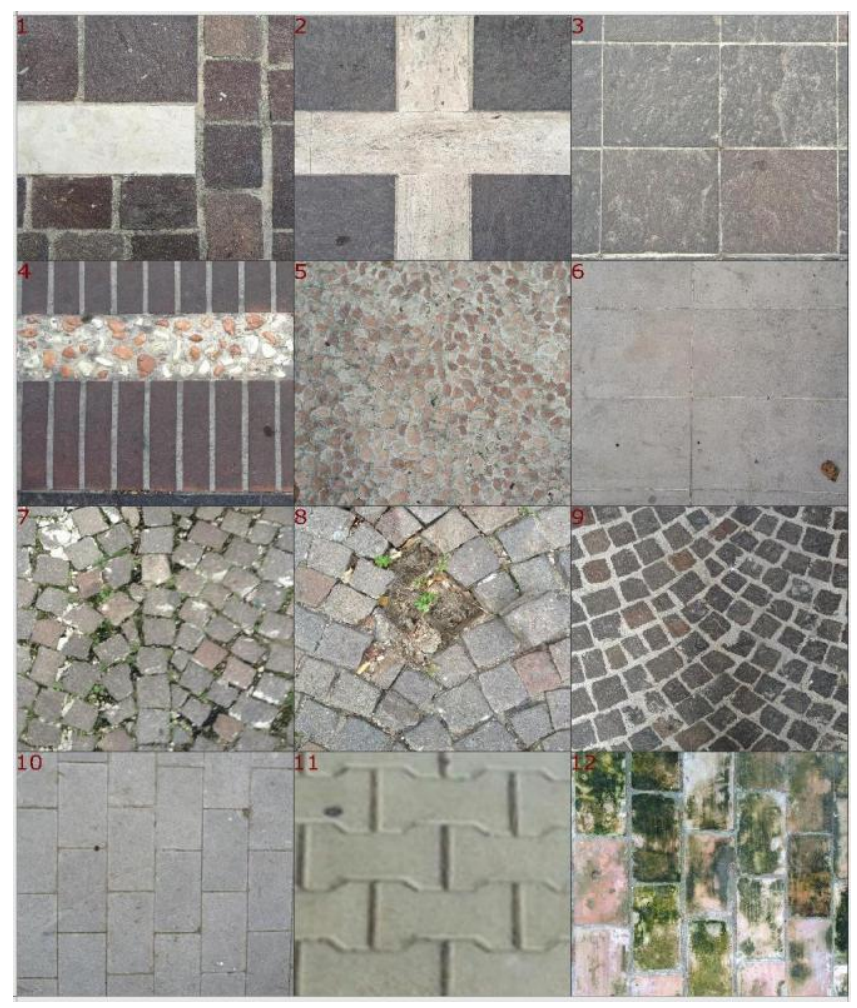

Fig. 5 The flooring types in Colonnella (limestone, porphyry stone, ...) 


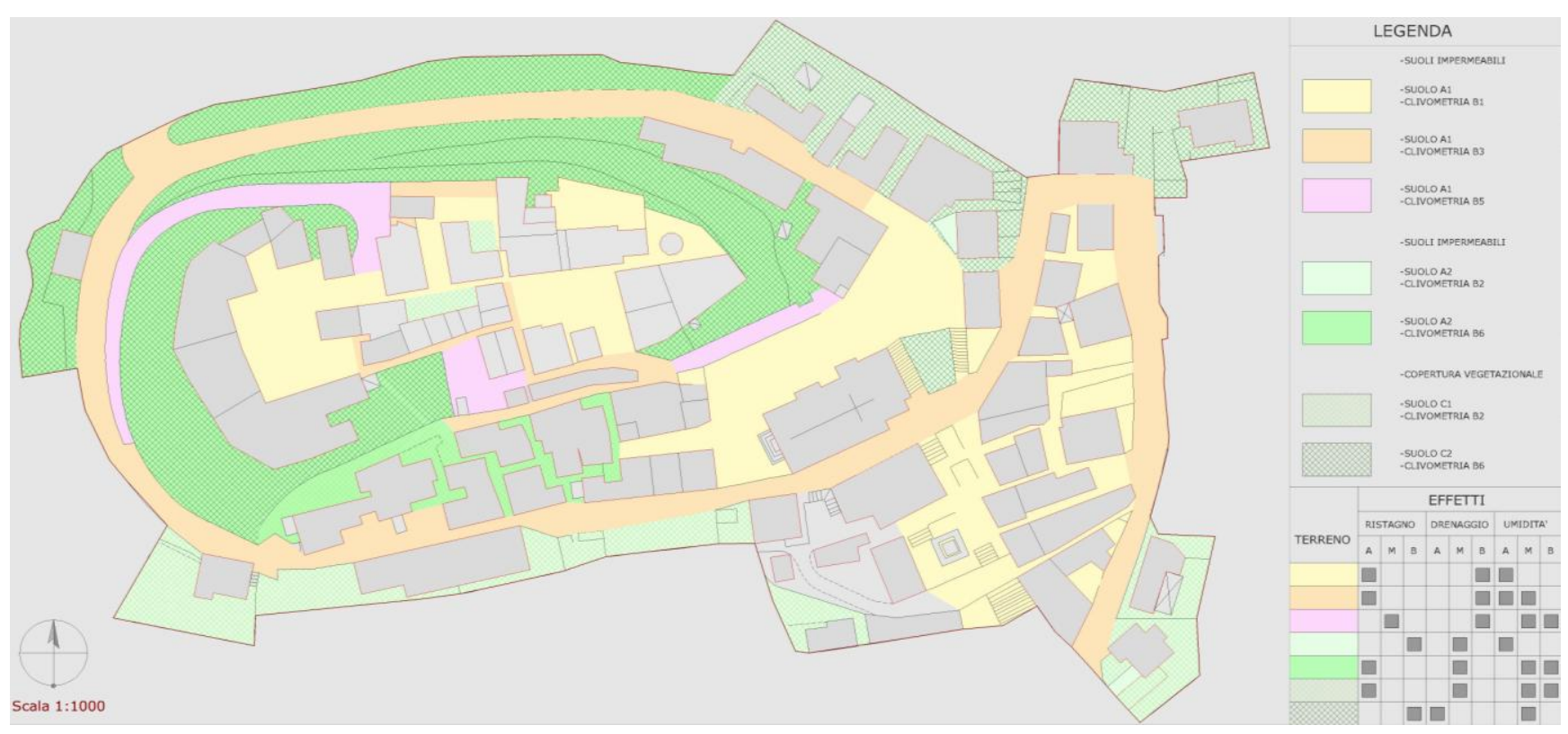

Fig. 6 The analysis of the soils. The first net in the right column identifies the soil with risk of humidity.

Rainwater harvesting uses channels to drain water from the impermeable surfaces. The collected water undergoes then a purification process through a double filtration so that even the smallest impurities will be blocked and pumped straight in to the drainage pipe, thus ensuring a high filtration efficiency even with a low-maintenance of the plant (see Fig. 7).

Finally, the project to improve the conditions of comfort for users of Largo Palazzo in relation to the effects of turbulence caused by excessive ventilation have been resolved by using barriers formed with plants. The choice of these apparently simple systems has been dictated by the need to preserve the values of the village. In fact, among the possible design solutions to fix the critical issues there was the modification of the morphological conformation of the point of entry of the wind into the little square. Although this solution seemed to be interesting, it turned out it was not feasible. In fact, this solution on one hand would have solved the environmental problem by enlarging the section of the wind flow thus avoiding the formation of wind turbulence.

On the other hand, however, it would have irreparably altered the volumetric and perceptual conformation of the little square, probably causing a condition of "non-recognition" by the user who lives in the village of Colonnella.

For this reason the choice of the barrier formed with plants turned out to be an efficient and above all compatible solution. It has been designed specifically for the context under study, following the information found in the analysis papers on the wind ventilation (in part, those in Fig. 4), from the point of view of location, shape and type of essence.

All the proposed solutions are efficient to solve the problems that occur in a given season but, at the same time, do not create uncomfortable conditions in the opposite season.

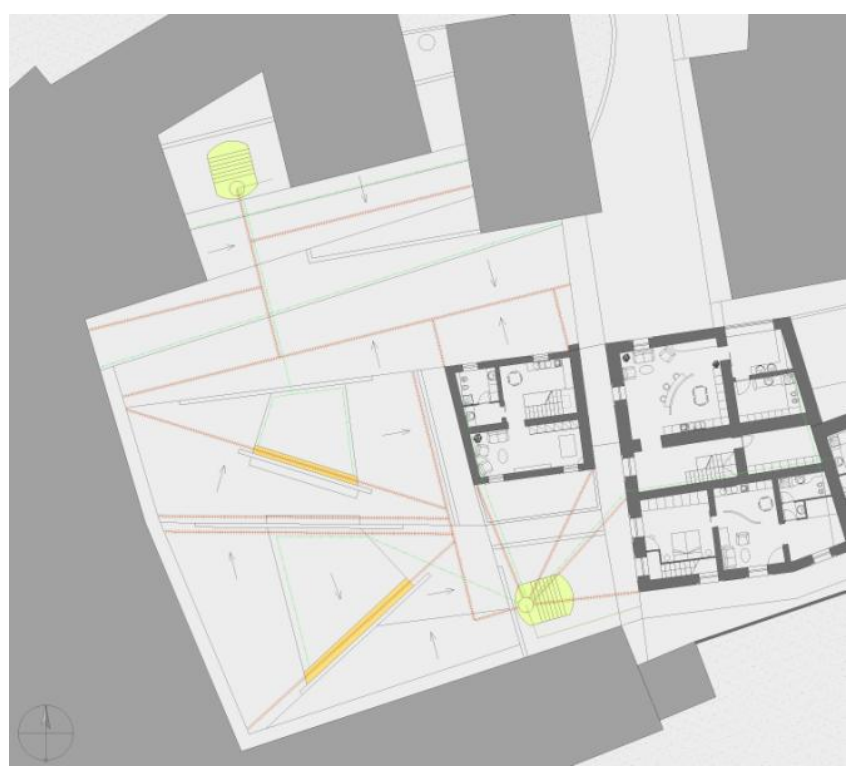

Fig. 7 Rainwater harvesting and channelization project. The system has been located below the floor level of Largo Palace. The orange lines identify the collection pipes while the green lines identify the water distribution pipes. The location of the two storage tanks is highlighted in yellow.

The analysis refers to an existing context, but it could be easily applied also to a new project from scratch. In fact, our cities are rich in outdoor open spaces that are like jewels as for architectural forms, choice of materials, symbolic meanings. Many of these places, however, are deserted, unable to fulfill the original function assigned to them by the designer who has planned them or the local authorities who have financed their construction project. In most cases, the "non-use "of these places depends from the fact that proper attention has not been paid to the conditions of urban comfort, causing "discomfort" in contemporary users. For this reason the above described methodology allows the identification of ad hoc design strategies for the context under study so to enhance comfort in open spaces. 


\section{ACKNOWLEDGMENT}

Authors wish to thank Eng. Silvia Carissimi for providing some of the images developed in her Master's thesis, "Progetto di riqualificazione sostenibile nell'edilizia storica di Colonnella", supervisor Prof. Eng. Pierluigi De Berardinis and $\mathrm{PhD}$. Eng. Marianna Rotilio.

\section{REFERENCES}

[1] M. Cirasa "Recupero degli spazi aperti di relazione nei centri storici minori" Roma: Gangemi Editore, 2011, ch. 1, pp. 28-30.

[2] P. De Berardinis and M. Rotilio, "Recupero sostenibile dell'edilizia minore. Coniugare l'efficienza ambientale con la qualità architettonica" in Proc. Città Energia Conf., Napoli, pp. 293-301, Brienza: Le Penseur, 2012

[3] N. U. Kofoed and M. Gaardsted "Considerazioni sul vento negli spazi urbani" in Progettare gli spazi aperti nell'ambiente urbano: un approccio bioclimatico, M. Nikolopoulou, Ed. Eptalofos S.A., Grecia: Centre for Renewable Energy Sources 2004, ch. 2, pp. 8-12.

[4] A.D. Penwarden and A.F.E. Wise, "Wind environment around buildings" Dept. of the Environment BRE, Her Majesty's Stationery Office, London, UK, 1975.

[5] M. Nikolopoulou and K. Steemers "Thermal comfort and psychological adaptation as a guide for designing urban spaces", Energy and Buildings, vol. 35, no.1, 2003.

[6] L. Katzshner, "Bioclimatic characterization of urban microclimates for the usage of open spaces" in Proc. Architectural and Urban Ambient Environment Conf, Nantes 2002.
[7] G. Scudo, A. Rogora, and V. Dessì "Thermal comfort perception and evaluation in urban space" in Proc. EPIC 2002 AIVC, Lyon 2002.

[8] D. D'Olimpo "La progettazione del microclima urbano. Le caratteristiche microclimatiche in ambiente urbano come fattori per la definizione della qualità ecosistemica dei sistemi insediativi” Roma: Edizioni Kappa, 2008, ch. 5.2.2, pp. 93-99.

Marianna Rotilio was born in L'Aquila, Italy, on 12.08.1980. She graduated in Building Engineering-Architecture at the University of L'Aquila, in 2005, with the mark of 110/110 cum laude, with a final project concerning the energy rehabilitation of Civitaretenga.

She is a freelancer and works in the field of post-seismic reconstruction. She earned the PhD in Architectural Engineering EU at the University of Pavia in 2011 and actually develops didactic activity in the University of L'Aquila. The main issue of research is related to the energy and sustainability and she has realized a lot of articles about this theme.

Pierluigi De Berardinis was born in Rome, Italy, on 13.02.1954 and graduated at the Faculty of Engineering of La Sapienza University in 1978 with the mark of 110/110 cum laude, with a final project concerning the open building systems for an infant school.

He worked as executive designer, work's director in building construction and as a consultant for public and private companies particularly in the field of farming management and direction of construction process. He is associated Professor of Technical Architecture. Since 1981 he is publishing articles and works on the themes of sustainable rehabilitation, construction procedures and management control. 